\title{
OS CONFLITOS NA ESCOLA NORMAL DE PIRACICABA EM MEADOS DA DÉCADA DE 1930 \\ DOI: http://dx.doi.org/10.1590/2236-3459/52821
}

\author{
Macioniro Celeste Filho \\ Universidade Estadual Paulista - campus de Bauru, Brasil.
}

\begin{abstract}
Resumo
Em 1934 a Escola Normal de Piracicaba enfrentou conflitos no processo de implantação do novo Código de Educação do Estado de São Paulo. Professores e a direção da escola discordavam quanto ao caráter normativo deste código. Enfrentava-se, também, divergência sobre o processo avaliativo do período. A autoridade administrativa foi então questionada e as disputas pelo poder institucional vieram à tona. Houve a necessidade de mediação externa nestes conflitos, demandando sindicância governamental sobre a situação beligerante nesta tradicional escola secundária. A análise destas disputas possibilitou a compreensão do cotidiano escolar de então e as múltiplas facetas da organização institucional deste importante estabelecimento de ensino.

Palavras-chave: ensino secundário, escola normal, Piracicaba.

\section{THE CONFLICTS IN NORMAL SCHOOL OF PIRACICABA IN THE MIDDLE OF THE 1930S}

\section{Abstract}

In 1934 the Normal School of Piracicaba faced conflicts in the process of implementing the new Education Code of the State of São Paulo. Teachers and the school principal disagreed about the normative nature of this code. There was also disagreement over the period of the evaluative process. The administrative authority was then questioned and institutional power struggles surfaced. There was the need for external mediation in these conflicts, demanding governmental inquiry on the belligerent situation in this traditional school. The analysis of these disputes made possible the understanding of the everyday of school and the multiple facets of the institutional organization of this important educational establishment.

Key-words: secondary education, normal school, Piracicaba.

\section{LOS CONFLICTOS EN LA ESCUELA NORMAL DE PIRACICABA A MEDIADOS DE LA DÉCADA DE 1930}

\section{Resumen}

En 1934 la Escuela Normal de Piracicaba enfrentó conflictos con el nuevo Código de la Educación del Estado de São Paulo. Los profesores y la dirección de la escuela estaban en desacuerdo en 
cuanto del carácter normativo de este código. Existía también desacuerdo sobre el proceso de evaluación escolar. La autoridad administrativa fue cuestionada y la lucha por el poder ha surgido. Hubo necesidad de la mediación externa en estos conflictos, exigiendo investigación del gobierno sobre la situación beligerante en esta tradicional escuela secundaria. El análisis de estos conflictos ha permitido la comprensión del cotidiano escolar y las múltiples facetas de la organización institucional de este importante centro de enseñanza.

Palabras-clave: escuela secundaria, escuela normal, Piracicaba.

\section{LES CONFLITS À L'ÉCOLE NORMALE DE PIRACICABA DANS LA MI-DECENNIE 1930}

\section{Résumé}

En 1934 l'École Normale de Piracicaba a fait face à des conflits pendant le processus de mise en œuvre du nouveau Code d'éducation de l'État São Paulo. Les enseignants et la direction scolaire étaient en désaccord sur le caractère normatif de ce code. II y a eu également un désaccord sur le processus d'évaluation de la période. L'autorité administrative a ensuite été mise en cause et les disputes par le pouvoir institutionnel surviennent. II a fallu une médiation externe dans ces conflits, exigeant une enquête gouvernemental de la situation belligérante dans cette traditionnelle école secondaire. L'analyse de ces conflits a conduit à la compréhension du jour au jour scolaire de l'époque et les nombreuses facettes de l'organisation institutionnelle de cet important établissement d'enseignement.

Mots-clé: enseignement secondaire, école normale, Piracicaba. 
A ssim como Maria Lúcia Spedo Hilsdorf afirma em seu clássico texto Lourenço Filho em Piracicaba que, inicialmente procurava uma coisa e achou outra, não era propósito nas minhas pesquisas recentes tratar da Escola Normal de Piracicaba. No levantamento dos relatórios das delegacias regionais do ensino do Estado de São Paulo, elaborados entre 1933 e 1945 e preservados no Arquivo Público do Estado de São Paulo, havia uma lacuna. Verificou-se que o nono relatório desta série, referente à Piracicaba, não fora incluído entre os demais documentos disponíveis na internet. Contatei o Arquivo sobre esta discrepância. Fui informado que, embora estivesse arquivado entre os demais relatórios, este documento de 311 páginas não era propriamente um relatório, mas o resultado da sindicância sobre os episódios conflituosos ocorridos na Escola Normal de Piracicaba em 1934.

Minha curiosidade se aguçou. Ao examinar esta sindicância constatei que as lutas internas da Escola Normal de Piracicaba estavam expostas. Como geralmente documentos administrativos apresentam a normalidade do funcionamento dos sistemas escolares, percebe-se que esta sindicância era rara exceção. Neste sentido, conhecer as desavenças, as disparidades de ação frente à norma, as interpretações conflitantes do que era legítimo na atuação institucional dos professores, administradores e alunos deste importante estabelecimento de ensino possibilita entender como a hierarquia educacional era constantemente rearticulada frente aos desafios contemporâneos. Os conflitos da Escola Normal de Piracicaba estão visíveis nas disputas relatadas em 1934. Cabe-nos compreender como uma escola exemplar efetivamente funcionava, perceber como as normas eram fluídas e testemunhar a história de uma importante escola normal sendo tecida dia a dia.

O enredo básico trata da recusa de um dos professores, Manassés Ephraim Pereira, em acatar o horário dos exames discentes estabelecido pelo diretor da escola, Fausto Lex, em julho de 1934. Os exames são suspensos e a sindicância é instaurada a pedido da direção da escola. Contudo, para entender o contexto do que se relatou é necessário retroceder em alguns meses dos acontecimentos conflitantes.

Frequentemente o primeiro período getulista, de 1930 a 1945, é apresentado como um crescente caminho para o autoritarismo, culminando em 1937 na ditadura do Estado Novo. Não é isto o que se vê na documentação referente aos anos de 1933, 1934 e até novembro de 1935, período anterior à repressão à Intentona Comunista. Nestes quase três anos os protagonistas comportaram-se como se presenciassem uma poderosa liberdade. No Brasil ocorria um dos raros períodos de otimismo democrático nos conturbados anos 1930. Pode-se dizer que existia uma verdadeira euforia democrática. Em 1934 a Assembléia Nacional Constituinte estava em plena atividade, sendo a nova Constituição promulgada em julho deste ano. Eleições legislativas se realizariam em outubro de 1934 nas quais, pela primeira vez, o voto feminino ocorreria sem restrições. Este clima democrático agitava as reivindicações por maiores liberdades e conquistas sociais. Não era diferente em Piracicaba.

Neste clima de vislumbre de que novas relações sociais, culturais e políticas poderiam ser criadas, os educadores paulistas confrontaram-se com duas mudanças institucionais que afetavam diretamente a Escola Normal de Piracicaba. Em 21 de abril de 1933 o sistema educacional paulista fora reorganizado com a edição do novo Código de Educação. Em 19 de agosto de 1933 ocorrera a assinatura do decreto estadual n. 6.047, 
que criou outra Escola Normal em Piracicaba. Seria a constituição da primeira escola normal rural no país. Estas duas mudanças abalaram a normalidade institucional em que se encontrava há décadas a Escola Normal de Piracicaba.

O Código de Educação pretendia racionalizar os diversos aspectos do funcionamento escolar em São Paulo. Embora tentasse antecipar e normatizar, preventivamente, as situações conflitantes dentro do sistema escolar, o Código não conseguiu tal propósito. Ao contrário, paradoxalmente, ao menos em Piracicaba, ele desencadeou rearranjos institucionais de maneira violenta e bastante conflituosa.

Para sanar possíveis dúvidas e insatisfações com o novo Código de Educação e amainar as incertezas advindas com a iminente criação de uma segunda escola normal na cidade foi realizado, de 26 a 28 de março de 1934, o Congresso Regional de Ensino de Piracicaba. Segundo a Gazeta de Piracicaba ${ }^{1}$, de 28 de março 1934, na cerimônia de abertura, entre diversas autoridades, estiveram presentes Francisco de Faria Netto, delegado regional do ensino, Fausto Lex, diretor da Escola Normal e José de Campos Camargo, inspetor escolar e futuro sindicante dos conflitos da Escola Normal. O primeiro dia do congresso foi destinado à organização e funcionamento dos cinco grupos de trabalho, que formulariam propostas sobre as atividades escolares da região.

Dentre as quatro palestras do congresso a mais importante foi a de encerramento, com a conferência de Sud Mennucci, piracicabano formado pela Escola Normal da cidade, ex-diretor geral do ensino, responsável pelo decreto de criação da Escola Normal Rural de Piracicaba, presidente do Centro do Professorado Paulista e diretor da Imprensa Oficial do Estado de São Paulo. O tema tratou dos Aspectos piracicabanos do ensino rural. A conferência foi uma veemente defesa da instalação em Piracicaba da primeira escola normal rural do país. Quem conhece congressos educacionais sabe quanto se discutem os mais diversos assuntos em seus bastidores. Certamente o novo Código de Educação e a criação da nova Escola Normal Rural de Piracicaba foram assuntos frequentes nas discussões paralelas ao evento.

Após o evento não se vislumbravam grandes conflitos. Aparentemente o Congresso Regional de Ensino havia cumprido seu papel de consolidar os laços de fraternidade intelectual na cidade e arrefecer as discordâncias frente à implantação das normas do Código de Educação. Além de também minimizar os medos do que ocorreria ao status quo intelectual de Piracicaba com a implantação efetiva de uma segunda escola normal na cidade. Contudo, eram demasiadas as incertezas e insatisfações latentes para qualificar os acontecimentos de julho de 1934 na Escola Normal como um raio em céu azul. Neste caso, um pequeno incidente de discordância quanto ao horário de aplicação de uma prova ganhou contornos inéditos.

${ }^{1}$ É necessário alertar para a dificuldade em usar os jornais piracicabanos deste período como fonte para pesquisa. As coleções de jornais preservadas no Instituto Histórico e Geográfico de Piracicaba contêm enormes lacunas. Nos primeiros anos da década de 1930 os dois principais jornais da cidade eram o Jornal de Piracicaba e a Gazeta de Piracicaba. No auge dos conflitos da Escola Normal, em meados de 1934, não foram preservados exemplares de jornais deste período. Não foi preservado nenhum exemplar do Jornal de Piracicaba do ano de 1934. A coleção da Gazeta de Piracicaba tem lacunas de vários meses neste ano. Portanto, as informações a partir destas fontes são bastante fragmentadas e descontínuas. Como norma, os artigos aqui citados são da primeira página do jornal. Caso não sejam, isto será informado. Os artigos citados não têm autoria determinada; caso isto ocorra, também será destacado. 
Os exames parciais da Escola Normal foram agendados para o final de julho de 1934. Existiam duas turmas de alunos para cada série do curso secundário regular. $O$ diretor, Fausto Lex, organizou os horários de provas de modo que as duas turmas de uma mesma disciplina fizessem os exames simultaneamente. Isto é, a banca examinadora, composta pelo professor da disciplina e dois outros docentes, deveria se mover intercaladamente entre duas salas onde estariam sendo aplicadas concomitantemente duas provas idênticas. No dia 20 de julho de 1934, Manassés Ephraim Pereira e os dois outros membros da banca de Francês aplicaram a prova a apenas uma das duas turmas do segundo ano do curso secundário. Na sequência aplicariam o exame na outra turma, que esperava sem nada a fazer na sala ao lado. Tomando conhecimento de que havia sido desobedecido no que estipulara como procedimentos de provas, Fausto Lex discutiu rispidamente com Manassés Pereira, cancelou a validade de suas provas e suspendeu os demais exames de toda a Escola Normal. No mesmo dia enviou telegrama ao diretor geral do ensino, o que hoje corresponderia ao secretário estadual de educação, na capital, solicitando providências. O diretor geral do ensino, Francisco Azzi, convivera profissionalmente com Fausto Lex anos atrás. Francisco Azzi fora professor na Escola Normal de Casa Branca nos anos 1920, enquanto o próprio Fausto Lex era diretor daquela escola. Isto é, Fausto Lex havia sido diretor de Francisco Azzi. Portanto, cada um deles conhecia o temperamento do outro. Para sanar a situação, em 24 de julho de 1934, Francisco Azzi nomeou José de Campos Camargo, inspetor escolar de Piracicaba, como sindicante dos conflitos da escola normal desta cidade.

Fausto Lex, nascido em Amparo, formou-se no Ginásio de São Paulo em 1902. Nas duas primeiras décadas do século foi professor de escola isolada e, depois, do Grupo Escolar de Barretos, onde lecionou por oito anos. Em 1920 tornou-se diretor do Grupo Escolar de Tatuí, ascendendo no final deste mesmo ano ao posto de delegado regional do ensino de Araraquara e em 1924 como delegado do ensino de São Carlos. Em 1925 foi nomeado diretor da Escola Normal de Casa Branca e em 1927 diretor da Escola Normal de São Carlos. Em 1932 foi transferido para a direção da Escola Normal de Piracicaba. Fausto Lex tinha 55 anos quando dos conflitos na Escola Normal de Piracicaba.

Manassés Ephraim Pereira, nascido na capital, concluiu seus estudos na Escola Normal de São Paulo em 1905, lecionando em seguida em escola isolada e no Grupo Escolar de Monte Alto. Em 1911 tornou-se professor e auxiliar do diretor da Escola Normal de Piracicaba. De 1917 a 1928 foi o vice-diretor desta escola. Concomitantemente lecionava no Colégio Piracicabano, importante escola privada da cidade. Ele tinha 48 anos quando se confrontou com o diretor da escola.

Em um mês de sindicância foram interrogados Fausto Lex, Manassés Pereira, o escriturário, o assistente geral e o secretário da Escola Normal, quatorze professores catedráticos, oito professores adjuntos do Curso Primário anexo à Escola Normal e oito alunos. A sindicância demonstrou detalhadamente os problemas da Escola Normal de Piracicaba. Quais eram os principais fatores a atrapalhar a normalidade institucional desta escola exemplar?

O principal fator desestabilizador causado pela administração de Fausto Lex em Piracicaba foi a tentativa de estabelecer a impessoalidade como regra na Escola Normal. Ele buscou tornar as atividades profissionais de sua escola procedimentos independentes das relações pessoais envolvidas. A impessoalidade, neutralidade e racionalidade da lei 
deveria substituir ou, ao menos, normatizar as funções profissionais até então personalizadas em relações de compadrio. Porém, como as relações de poder se estabelecem entre setores sociais privilegiados, tentar despersonalizar tais relações foi mexer num vespeiro inaudito. Até a chegada de Fausto Lex a direção da escola mediava as relações entre os docentes, entre os docentes e os alunos e entre os docentes e o Estado. Estas relações eram cotidianamente negociadas e reformuladas caso a caso, pessoa a pessoa. A direção usava o sucesso de sua mediação entre as relações pessoais sob sua confiança como fonte da autoridade do diretor. Ao tentar transformar isto numa administração baseada no Código de Educação, Fausto Lex solapou a estabilidade do aos amigos, tudo; aos inimigos, a lei. Ele quis estabelecer a lei para todos, impessoal, como o princípio administrativo a fundar a autoridade. Para os setores sociais privilegiados pela ordem anterior, isto era inadmissível. Fausto Lex foi identificado como alguém que queria impor a lei, logo, ele era visto como se estivesse tratando com inimigos e, de fato, inimigos não faltaram.

Para Fausto Lex as relações profissionais mescladas com relações pessoais de compadrio eram vistas como anômalas situações de privilégio. Ao explicar à autoridade sindicante a raiz de suas desavenças com Manassés Pereira, o diretor afirmou que isto se devia a não concordar que uma professora substituta continuasse a ser remunerada mesmo sem estar presente na escola, apenas por ser esposa de um professor catedrático. No caso ele explicou isto diretamente à esposa de Manassés Pereira, que em seguida se exonerou:

Fausto Lex: [O início da discórdia deu-se por] ter extinto uma situação de privilégio de uma substituta efetiva do Curso Primário anexo. [...] Tendo assumido a direção deste estabelecimento em janeiro de 1932, ao se reabrirem as aulas, notei que as substitutas efetivas tinham péssima assiduidade e entre elas estava a senhora [esposa] do professor Manassés, dona Hermantina. Reuni-as e fiz ver que as substitutas não podiam faltar assim. [...] Logo depois, a esposa do sr. Manassés exonerouse, talvez mal satisfeita. Era uma das que tinham fraca frequência. (Camargo, 1934, p. 7 verso e 10)

Existia consenso entre os inquiridos de que a ordem melhorara na Escola Normal desde a chegada de Fausto Lex à direção:

Manoel Dias de Almeida, catedrático da Escola Normal: Quanto à disciplina do estabelecimento, a direção atual conseguiu melhorá-la sensivelmente em relação à existente na direção anterior. (Camargo, 1934, p. 48 verso)

Um dos depoentes, a aluna Maria Dirce Rodrigues de Almeida, atribuiu a anarquia reinante na escola durante a administração anterior ao caráter bondoso do antigo diretor. Bondade e relações de compadrio seriam incompatíveis com a ordem. Neste sentido, Fausto Lex trouxera melhorias, contudo, a ausência de bondade é identificada como rispidez e aspereza nos modos de tratamento pessoal. Parece que existia o desejo contraditório de que o diretor colocasse ordem na escola, mas que simultaneamente fosse cordial: 
Maria Dirce Rodrigues de Almeida: Na administração do professor Lourival de Queiroz, devido à excessiva bondade deste, a escola estava um tanto anarquizada; o professor Fausto Lex teve necessidade de usar de muita energia, o que causou natural estranheza aos alunos habituados com o regime anterior; apesar de bom diretor, não deixa de ser o professor Fausto Lex ríspido e áspero no tratamento geral com alunos e professores, parecendo ser esse o seu modo habitual. (Camargo, 1934, p. 138 verso)

Quais as atribuições de uma direção ordeira? Inicialmente administrar de maneira equânime os tempos escolares. Sobre isto Fausto Lex se apresentava como alguém ponderado. Até mesmo mudara o horário de aulas daquele ano letivo para favorecer aos professores que lecionavam concomitantemente em outras escolas secundárias de Piracicaba. Referindo-se a Manassés Pereira, o diretor apontou esta flexibilidade:

Fausto Lex: Nunca o prejudiquei em nada, tanto assim que the atendi à vontade, adotando o horário de aulas que organizara, [...] horário esse que fizeram para servir aos interesses dos professores que dão aula em outros estabelecimentos [de ensino] e não ao interesse dos alunos. (Camargo, 1934 , p. 7 verso e 8 )

Porém, tudo tinha limites. Fausto Lex não poderia abdicar em estabelecer os horários dos exames, causa imediata dos conflitos que deram origem à sindicância:

Segundo Fausto Lex, Manassés Pereira havia dito que "O sr. já não marcou os exames como eu quero". Ao que teria respondido: ObtempereiIhe que isto de marcar exames é atribuição dos diretores e ainda the expliquei que se assim organizei foi para atender a melhor conveniência do ensino, com participação ainda à autoridade superior, não havendo também disposição regulamentar alguma que me impedisse de determinar por essa forma. O sr. Manassés interrompeu-me querendo dizer - "O diretor do Ginásio Piracicabano..." - ao que eu, por minha vez, interrompi, dizendo: "Não tenho nada que ver com o Ginásio Piracicabano; lá, quem determina é o diretor Mr. Cooper e aqui é o diretor Fausto Lex". Mal acabei de terminar, o professor Manassés gritava: "O sr. quer impor, mas, nós não obedecemos; não faço exames como quer e hei de lhe mostrar". (Camargo, 1934, p. 8)

Segundo alguns depoentes, o restabelecimento da ordem por Fausto Lex tinha por indício o término dos namoros escandalosos na porta da Escola Normal:

Elpídio Godói de Oliveira, escriturário da Escola Normal: A disciplina do estabelecimento melhorou muito com a administração de Fausto Lex, estando quase que extinto o namoro escandaloso que anteriormente existia na frente da própria escola, entre alunos. (Camargo, 1934, p. 52 verso)

O controle dos tempos escolares e da moral social nas vizinhanças de seu estabelecimento de ensino eram vistos como pressupostos da autoridade do diretor. Contudo, a base primordial desta autoridade estava em manter a disciplina. Nos depoimentos, frequentemente, autoridade e disciplina são descritos quase que em paralelo. Uma era a medida da outra. Neste sentido, Manassés Pereira era visto por seus colegas e alunos como desprovido de autoridade: 
Antonio Martins Belmudes de Toledo, catedrático de Psicologia: $\mathrm{O}$ professor Manassés não mantém a disciplina na sua classe, tendo o depoente se visto na necessidade de fechar as portas de sua sala de aula para que não fossem os seus trabalhos prejudicados pelo barulho causado pelas discussões dos alunos da classe de Francês. (Camargo, 1934, p. 30 verso)

Neste caso havia a necessidade de intervenção do diretor. O diretor usara sua própria autoridade para manter a ordem nas aulas de Manassés Pereira, mas este professor questionava esta mesma autoridade quando Ihe convinha. Para Fausto Lex, isto não era correto:

Fausto Lex: É ele [Manassés Pereira] quem mais precisa de mim, pois não mantém disciplina em classe e, se não fosse a minha autoridade, não poderia mais trabalhar. (Camargo, 1934, p. 8 verso)

O processo de restaurar a disciplina, romper com as relações profissionais baseadas no compadrio e tentar estabelecer o Código de Educação como base da autoridade administrativa teve como resultado imediato o afloramento das contradições educacionais do período e a eclosão de contínuos surtos de violência escolar. Fausto Lex foi obrigado a lidar então com as frequentes manifestações de violência no cotidiano da Escola Normal. Algumas protagonizadas pelo próprio diretor. Embora estejam associados, podem-se distinguir estes surtos agressivos entre violência verbal e violência física.

Os professores manifestaram inconformismo com a violência e incontinência verbal do diretor. Neste caso a autoridade se desmanchava em autoritarismo, desencadeando a desarmonia no ambiente escolar:

Francisco Mariano da Costa, catedrático de Matemática: O diretor Fausto Lex é autoritário, impulsivo, violento e grita com os professores, usando de expressões grosseiras que irritam, tendo por sistema contrariar as opiniões; esta autoridade [o diretor] não guarda reserva de assuntos que não devem passar além do conhecimento da parte interessada, acarretando o ambiente de desarmonia existente nesta escola. (Camargo, 1934, p. 75)

Acuado, Fausto Lex atribuía a violência verbal a Manassés Pereira, pois este professor não possuía autoridade:

Fausto Lex: Em geral, de uns tempos para cá, o professor Manassés quase que só fala em voz alterada. Seria bom que fossem ouvidos os alunos da quinta série mista e da quarta mista para que digam com quanta aspereza o professor em questão os têm tratado. (Camargo, 1934, p. 11 verso)

Alguns alunos confirmaram a agressividade verbal de Manassés Pereira. A violência verbal descambara para a ofensa generalizada quando este professor chamou de cachorrada alunos e alunas de uma classe mista:

Antonio Camargo de Almeida Prado, dezenove anos, aluno do Curso de Formação de Professores: [O professor Manassés Pereira] excedia-se às vezes nas repreensões que fazia à classe, gritando com os alunos, pondoos para fora da classe, de modo que os estudantes sentiam-se humilhados 
com essa atitude; essa exasperação do professor Manassés era devida à falta de disciplina dos alunos, consequência talvez do cansaço do mestre que tem muitos anos de magistério; certa vez, o professor Manassés perdeu o controle de seus nervos e, exasperado, chegou a chamar a classe toda de cachorrada, classe essa mista, desse fato lembro-me bem. (Camargo, 1934, p. 139 e 139 verso)

Segundo estes depoimentos a violência verbal humilhava os alunos, o que atingia a honra dos estudantes. É apropriado ressaltar que não se tratava de crianças ou adolescentes. Os alunos estavam na faixa etária de dezoito a vinte e um anos de idade:

Manoel da Silva Matos, vinte e um anos, aluno da quinta série do Curso Fundamental: O professor Manassés é um bom professor, conhecedor da matéria que leciona, mas não tem disciplina em classe por ser muito nervoso e ríspido no tratamento com os alunos, gritando por motivos de somenos importância e mesmo humilhando seus discípulos perante os demais alunos da classe, como já aconteceu com o depoente no ano passado; a todo momento há desavenças entre alunos e aquele professor, devido ao seu modo ríspido, que irrita os brios dos estudantes. (Camargo, 1934, p. 129 verso)

Manassés Pereira justificou-se dizendo que não tivera propósitos ofensivos:

Manassés Pereira: Se porventura eu houvesse usado [em classe] da expressão cachorro para com algum aluno, teria empregado a palavra com o sentido de "mal educado" ou "sem educação", não, porém, com o sentido pejorativo. (Camargo, 1934, p. 141)

Da violência verbal para a ameaça de violência física, a distância não era longa. Manassés Pereira acusou o diretor de ameaçar bater em outros professores.

Fausto Lex: Tenho sabido e percebido que há professores que na sala dos professores e na portaria, como também no saguão desta escola, falam mal de mim, criticando-me os atos, e que se calam à minha aproximação; em certa ocasião, falando em tese sobre os desaforos que naquelas conversas assacavam-me, disse que precisavam ter cuidado, porque se me dissessem qualquer desaforo, como homem reagiria, metendo a mão na cara. (Camargo, 1934, p. 132 verso)

Da ameaça de violência física à violência física efetiva, a distância era menor ainda. A maioria dos alunos inquiridos relatou o uso de violência física por parte do diretor. É oportuno recordar que eram alunos de no mínimo dezoito anos de idade. Tratava-se de violência física entre adultos:

Herbert Silveira da Costa, dezoito anos, aluno da quinta série do Curso Fundamental: O diretor Fausto Lex trata os alunos com brutalidade, aos gritos, não aceitando explicações, tendo mesmo dado pescoções nos alunos de nome Caetano Orlando e João Boller Hueffembach, tendo este sido atirado pela escada abaixo. (Camargo, 1934, p. 129) 
O diretor não negou o uso eventual de violência física com os alunos. Contudo, justificou tal ato exacerbado em um caso apenas, de forte desaforo:

Fausto Lex: Por ter ouvido de um aluno um desaforo forte, tive necessidade de segurá-lo pelo paletó e obrigá-lo a sair; esse aluno, de nome João Hueffembach, voltou logo a seguir e pediu desculpas do que fez, sendo atendido e aconselhado por mim, que lhe apertei as mãos. (Camargo, 1934, p. 132 verso)

A violência, quando humilhava e atingia a honra dos estudantes, às vezes, não ficava sem reação. Tal violência transbordava então do ambiente escolar para as ruas de Piracicaba:

José Calil, vinte anos, aluno do segundo ano do Curso de Formação de Professores: Ouvi, há tempos, de alguns alunos do Curso Fundamental, entre os quais o de nome Ademar Spallini, que havia um grupo de alunos que constantemente tinham desavenças com o professor de Francês [Manassés Pereira], o qual os mandava para a diretoria; que, a princípio, o diretor Fausto Lex os repreendia, mas, como os incidentes se reproduzissem com muita frequência, já o diretor não tomava mais conhecimento desses fatos. (Camargo, 1934, p. 128)

Manassés Pereira: Já fui cercado na rua pelo próprio aluno Ademar Spallini, tendo sido o fato levado ao conhecimento do diretor [Fausto Lex]; também o pai desse mesmo aluno me desacatou em plena rua, tendo sido ameaçado de agressão física. (Camargo, 1934, p. 140 verso)

Mesmo que esta violência cotidiana possa ser vista, atualmente, como inapropriada, não se deve incorrer em anacronismos. Alguns depoentes narraram estes atos violentos como se fossem normais. Não gostavam desta violência, mas atestavam sua eficácia. $A$ violência era, às vezes, identificada como a manifestação da energia da autoridade, uma violência positiva e justificável, sendo socialmente aceitável:

Caetano Orlando, dezoito anos, aluno da quinta série do Curso Fundamental: O professor Fausto Lex, em começo de sua administração, era violento, gritando com os alunos e safanando-os, como aconteceu comigo. Por atos praticados por outros dois alunos, fui tomado pelo braço pelo diretor, com violência, e empurrado para o gabinete [da direção] onde fui repreendido por ele, que me ameaçou atirar pela janela abaixo. Nunca mais houve incidente comigo. Devido à energia do professor Fausto Lex, a disciplina do estabelecimento melhorou bastante. (Camargo, 1934, p. 141 verso)

Com estes surtos sequenciais de violência escolar, de inimizade entre os professores e de desarmonia entre os professores e o diretor, alguns professores e também o diretor, às vezes, iam trabalhar armados na Escola Normal:

Antonio de Padua Dutra, catedrático de Desenho: Não há harmonia no corpo docente do estabelecimento [...] sendo quase geral a incompatibilidade dos lentes entre si, [...] houve tempo em que alguns professores vinham armados ao estabelecimento, tal era a animosidade entre eles. (Camargo, 1934, p. 44) 
Fausto Lex: Embora não possa garantir, soube que, ou melhor, desconfiei que um professor vinha armado ao estabelecimento; é possível eu também ter vindo armado ao estabelecimento, mas sem qualquer intuito agressivo. (Camargo, 1934, p. 134)

Foi neste ambiente hostil que Fausto Lex percebeu a oportunidade de saída desta situação: o Código de Educação de 1933. Assim como Thomas Hobbes expôs, no século 17, que o medo da violência continuada levaria a se optar pela submissão de todos ao Estado, Fausto Lex viu no Código de Educação a plena instituição do poder legítimo do Estado em sua escola. Neste intuito, os atos do diretor baseavam-se obsessivamente no novo Código de Educação:

Anísio Ferraz Godinho, assistente geral da Escola Normal: O professor Fausto Lex [...] às vezes [fica] excessivamente dentro do regulamento, isto é, interpretando a lei no sentido restrito; digo, interpretando estritamente a lei. (Camargo, 1934, p. 59 verso)

Thales Castanho de Andrade, catedrático de História da Civilização: O diretor tem a obsessão da lei, exagerando o seu cumprimento e cingindose à letra da mesma, considerando mesmo um ato de desconsideração para consigo o fato de qualquer professor procurar interpretar a lei em discordância com a sua hermenêutica. (Camargo, 1934, p. 122)

Fausto Lex percebia poucas nuances na constituição da legitimidade de sua autoridade. Para o diretor a autoridade estava condicionada ao imperativo da ordem. Durante sua administração ele tentou por ordem no mais complexo, confuso e espinhoso aspecto da vida escolar da Escola Normal de Piracicaba: suas avaliações. Ele tentava acabar com as colas nos exames, entendida como fraude no processo avaliativo, quando alunos usavam de procedimentos escusos para responder as provas de avaliação de seu desempenho educacional. Muitos depoentes destacaram o papel moralizador de Fausto Lex em atacar a prática generalizada de colas nos exames da Escola Normal:

Hélio Penteado de Castro, catedrático de Física: A cola era desbragada, largando os alunos seus apontamentos, especialmente confeccionados para os exames, pelas vias públicas, apontamentos estes que eram colhidos por alunos de outras escolas; a direção de Fausto Lex conseguiu corrigir em grande parte esses abusos. (Camargo, 1934, p. 39 verso)

Havia então disparidade de atitudes: alguns professores eram coniventes com a cola e outros não. Até os próprios alunos destacaram que isto trazia injustiça, pois quem estudava e não colava se prejudicava:

Herbert Silveira da Costa, de dezoito anos de idade, aluno da quinta série do Curso Fundamental: Há muita cola neste estabelecimento, [...] resultando levar desvantagem nas notas os alunos que estudam e não colam. (Camargo, 1934, p. 129)

Foi neste contexto que eclodiu o testemunho mais bombástico desta sindicância: o depoimento de Francisco Mariano da Costa. O catedrático de Matemática acusava Thales de Andrade, catedrático de História da Civilização, e Silvio de Aguiar Souza, professor interino de Português, de serem coniventes com a cola em seus exames. Manassés 
Pereira era alguém ligado a estes professores. Manassés Pereira, ao protelar as provas de julho de 1934, apenas criara uma cortina de fumaça para obscurecer o real conflito na Escola Normal de Piracicaba: a intolerância da maioria dos catedráticos e do diretor com a fraude generalizada dos exames e a conivência de uma minoria docente com as colas. Segundo Francisco Mariano da Costa as fraudes nos exames ocorriam de duas maneiras: professores que deixavam os alunos consultar anotações e outros materiais didáticos em plena prova, o que era proibido, ou professores que entregavam previamente aos alunos, dias antes da prova, os pontos e as questões que nela seriam abordados. Isto ocorria desde a direção anterior, a do diretor bondoso, Lourival de Queiroz, e pelo longo período em que Manassés Pereira fora vice-diretor da escola. Em parte por pressão docente Fausto Lex foi forçado a acabar com esta situação e a moralizar os exames na Escola Normal, daí o verdadeiro conflito nesta escola.

Francisco Mariano da Costa narrou a escalada dos acontecimentos envolvendo o combate às fraudes nos exames e exemplificou como elas ocorriam. Ele não tolerava as colas. Em julho de 1933, exatamente um ano antes dos conflitos que deram origem à sindicância, fora escalado para uma banca de exames de História da Civilização, presidida por Thales de Andrade. Notando que os alunos não conseguiriam responder satisfatoriamente sem cola a prova de História, Thales de Andrade indicou a necessidade de Francisco Mariano da Costa se ausentar momentaneamente da sala de provas para que a fraude pudesse acontecer:

Francisco Mariano da Costa, catedrático de Matemática: Thales de Andrade me sugeriu, nos exames de julho do ano anterior, que "se quisesse sair para pitar [fumar], poderia fazê-lo"; como permanecesse na sala, o mesmo professor Thales dirigiu-me a palavra perguntando-me se insistia em ficar e, voltando-se para os alunos, disse a estes: "vocês estão vendo que ele insiste em ficar". (Camargo, 1934, p. 75 verso)

Francisco Mariano da Costa recusou-se a continuar nesta banca examinadora por suspeitar que os exames estivessem com seu sigilo fraudado. Retirou-se, portanto, da sala dos exames de História, o que consequentemente invalidaria estes exames:

Francisco Mariano da Costa: Quando já me achava no corredor, fui chamado pelo professor Thales, que perguntou: "Mariano, você quer abrir luta comigo?" Respondi: "não quero, mas não receio"; ato contínuo vim ao gabinete [da direção] e, respeitosamente, pedi ao diretor a sua dispensa da fiscalização dos exames de História da Civilização, em virtude das declarações tendenciosas feitas pelo professor Thales perante a classe, pedindo também providências no sentido de corrigir essa gravíssima situação. [...] O diretor, passando as mãos pelos cabelos, disse então: "Mariano, você acaba de criar a maior dificuldade que surgiu em minha carreira". (Camargo, 1934, p. 75 verso)

Fausto Lex conhecia as relações de Thales de Andrade com Sud Mennucci e, principalmente, com Monteiro Lobato. Dos professores da Escola Normal de Piracicaba Thales de Andrade era o docente com melhor trânsito entre a elite intelectual paulista do período. Suas obras de literatura infantil precederam e influenciaram a literatura infantil de Monteiro Lobato. As concepções do mundo rural nelas contidas dialogavam com a visão ruralista e de educação rural de Sud Mennucci. Se a Escola Normal Rural de Piracicaba 
fosse efetivamente implantada Thales de Andrade tinha fortes chances de ser seu primeiro diretor. Fausto Lex sabia que se indispor com este professor seria a maior dificuldade que surgira em sua carreira. Em 1933 a solução foi paliativa. Enquanto Francisco Mariano da Costa, na sala da direção, se recusava a voltar para os exames de História, Antonio de Padua Dutra, catedrático de Desenho, adentrou a sala e disse: "Sr. Fausto Lex, pela minha honra, eu lhe declaro que os exames [de História] da quinta série, de onde o sr. Mariano acaba de sair, ocorrerão na maior ordem, pois o sr. Thales me mandou para lá" (Camargo, 1934, p. 75 verso).

Fausto Lex substituiu emergencialmente Francisco Mariano da Costa por este professor na banca de exames de História da Civilização. Enfim, os catedráticos da Escola Normal de Piracicaba sabiam quem permitia e quem não permitia cola nos exames discentes. Em maio de 1934 Francisco Mariano da Costa, Dulce Ribeiro e Silvio de Aguiar Souza, professor interino de Português, compunham a banca de exames desta disciplina:

Como anteriormente, já tinha o depoente [Francisco Mariano da Costa] conhecimento de que os alunos estavam a par das questões que deviam entrar em sorteio, e, assim, procurou observar e averiguar a procedência ou não desse fato; que sorteado o ponto pelo respectivo catedrático [interino], prof. Silvio de Souza, a classe teve tais expressões de satisfação, fazendo ruído semelhante àqueles que se ouvem nos cinemas, manifestação esta que mais acentuou a convicção mencionada; que o depoente comunicou à professora Dona Dulce a impressão que tinha de que os alunos conheciam de antemão os pontos e as questões, respondeu-lhe a referida professora que era por isto que o sr. Fausto Lex estava nervoso. [...] Havendo então o depoente procurado o diretor do estabelecimento para pedir providências no sentido de se escusar ao julgamento das provas, [ouviu] do assistente geral [da Escola Normal, Anísio Ferraz Godinho]: "eu também percebi tudo"; que, levando mais tarde ao professor Fausto Lex o conhecimento do acontecido e reiterando o pedido de providências [ao que Fausto Lex constatou que o mesmo ocorrera com as demais séries nos exames de Português], terminando o diretor [por dizer]: "então, [que] aconteça o que [tiver que] acontecer". (Camargo, 1934, p. 76 verso)

Silvio de Aguiar Souza não era professor catedrático. Neste caso os exames de Português foram invalidados por Fausto Lex. Novos exames foram marcados posteriormente.

Dulce Ribeiro, professora assistente de Português, confirmou à autoridade sindicante tudo o que declarara anteriormente Francisco Mariano da Costa. Ela apresentou duas outras informações importantes em seu depoimento:

Dulce Ribeiro: ouvi dizer haver o professor da cadeira de Português [Silvio de Aguiar Souza] dado aula aos seus alunos no Centro do Professorado Piracicabano, no período decorrido entre a anulação dos exames e a designação de dia para os novos exames. (Camargo, 1934, p. 91 verso)

Isto é, Dulce Ribeiro suspeitava que o esquema de fraude dos exames continuasse, porém, com o vazamento das informações ocorrendo no contato direto de Silvio de Aguiar Souza com seus alunos no Centro do Professorado Piracicabano. A outra informação 
importante fornecida por ela (Camargo, 1934, p. 92) foi que na segunda prova de Português, possivelmente também fraudada, Francisco Mariano da Costa havia sido substituído na banca examinadora pelo professor Manassés Pereira.

Sob pressão, Fausto Lex teve que declarar oficialmente que não toleraria fraudes nos exames de meados de 1934. Em 11 de julho de 1934 Fausto Lex mandou fixar comunicado na sala dos professores quanto às fraudes:

Fausto Lex: NOTA IMPORTANTE: Os alunos em caso algum poderão ter conhecimento dos pontos. Em caso de infrações serão responsabilizados os infratores. (Camargo, 1934, p. 95)

Dias depois a recusa de Manassés Pereira em acatar o horário de provas discentes estabelecido pelo diretor foi apenas a gota d'água deste longo processo conflituoso.

Existia então uma espécie de hipocrisia educacional. Os exames sobre os conteúdos ministrados em aula eram rigorosíssimos. Porém, inexequíveis para os alunos. A solução encontrada era facilitar o uso da cola para que os alunos fossem bem sucedidos nas provas. Comprovava-se, portanto, ao menos documentalmente, o alto grau de ensino e de aprendizagem. Qual a proposta de Fausto Lex para debelar esta hipocrisia consentida e aperfeiçoar a avaliação educacional em sua escola? O diretor tentou duas coisas simultaneamente: acabar com as fraudes nos exames e, concomitantemente, torná-los mais fáceis, incluindo, quando possível, atividades de aula no processo avaliativo e não somente as provas periódicas. O diretor usava as deliberações da Diretoria Geral do Ensino e o novo Código de Educação como alicerces de suas tentativas em inovar nas avaliações da Escola Normal. Isto foi percebido por parte dos professores como interferência indevida nas atribuições docentes. Somente quando houve pressão dos alunos tais mudanças nas avaliações puderam ser cogitadas concretamente, muitas vezes contra a vontade dos professores envolvidos.

$\mathrm{Na}$ sindicância sobre os conflitos da Escola Normal em meados de 1934 existem dois exemplos desta proposta, baseada na nova legislação, em tornar os exames mais fáceis. Não por coincidência uma destas tentativas, decorrente da pressão discente, ocorreu com os exames do professor Manassés Pereira. Na prova de Francês, de 27 de julho, Manassés Pereira proibiu o uso de dicionários, o que havia sido autorizado previamente por Fausto Lex. Alguns alunos, entre eles Ademar Spallini, que anteriormente havia esperado com seu pai fora da escola para agredir fisicamente a Manassés Pereira, se recusaram a fazer os exames sem o uso de dicionários. Novamente o conflito se instaurou e a autoridade do diretor foi requisitada para resolver a discordância quanto aos procedimentos de avaliação:

Manassés Pereira: Quando estavam na sala a banca examinadora e os alunos da quarta série mista para fazerem exame de Francês, como lente da cadeira e presidente da banca determinei que os examinandos que tivessem dicionários consigo, os colocassem sobre a cátedra. Não sendo obedecido no momento por alguns alunos, notadamente por Ademar Spallini e [João] Narche, os quais dizendo que não atendiam por haver o diretor declarado poderem eles usar dicionário, insubordinaram-se contra a ordem dada. À vista disso, declarei que não fariam o exame se não fosse obedecido. O aluno [João] Narche, logo a seguir, levantou-se e declarando que sem dicionário não faria exame, dirigiu-se para a porta para sair. [...] Heli Mendes, [João] Narche e Ademar Spallini portaram-se muito 
inconvenientemente. Quando o diretor e os outros colegas de banca deram entrada na sala, dirigi-me àquele e pedi a punição dos três alunos mencionados. O diretor, após ligeira indagação, respondeu que não poderia tomar providências. (Camargo, 1934, p. 26 e 26 verso)

Fausto Lex: Ao entrar na sala, o professor Manassés pediu que eu punisse três alunos que promoviam indisciplina. [...] Verificando que nada houve de grave que impedisse àqueles alunos de prestar o exame, declarei perante os membros da banca que não poderia aplicar uma penalidade. [...] Alguns alunos apresentaram-me queixa do sr. Manassés, que os estava impedindo de usar dicionário. Mostrei aos alunos e pedi a um membro da banca que mostrasse ao sr. Manassés cópia da circular de 15/04/32, em que declara nas instruções para exames ser permitido o uso de dicionário. $\mathrm{O}$ incidente ficou momentaneamente resolvido por intervenção do professor Helio Penteado de Castro, negando-se o professor Manassés a permitir o uso de dicionário. (Camargo, 1934, p. 25)

Fausto Lex interferiu diretamente na avaliação de um professor, com a justificativa de que normas federais facilitavam os exames. Uma vez que era possível exames mais fáceis e que evitassem a necessidade de cola, por que não aplicá-los desta maneira? Esta era a lógica do diretor. Contudo, Manassés Pereira sentiu-se invadido em suas atribuições docentes e resistiu às mudanças. As mudanças somente ocorreriam com a pressão dos alunos, que gradativamente tomavam conhecimento das normas que, em alguns casos, favoreciam os interesses discentes. Simultaneamente os estudantes lutavam pela mudança na legislação referente aos exames.

A pressão estudantil, entre outras maneiras, ocorria na recusa em comparecer às aulas com o propósito de mudar os processos de avaliação. Em carta de 24 de julho de 1934 ao diretor Fausto Lex, os alunos explicavam os motivos de discordarem do processo avaliativo da disciplina de Desenho:

Nós, alunos dos $1^{\circ} \mathrm{s}$. e $2^{\circ} \mathrm{s}$. anos do Curso Profissional, $4^{\mathrm{a}} \mathrm{s}$ e $5^{\mathrm{a}} \mathrm{s}$. séries do Curso Fundamental, simples expoentes de um ideal coletivo, confiantes sinceros nas altas qualidades de espírito, de caráter e de justiça de que V. S. é possuidor, e considerando que a atuação do sr. professor de Desenho tem sido prejudicial aos alunos, como se pode constatar pelo seguinte: a) os trabalhos que somos obrigados a fazer em casa, para efeito de notas, são demasiados tanto em qualidade como em quantidade; b) tais trabalhos nem sempre estão ao nosso alcance e na maioria das vezes vêm prejudicar o devido estudo de outras matérias que se fazem mais necessárias à direção que temos em vista, sem com isto querermos desmerecer a citada cadeira de Desenho; c) mesmo satisfeitas todas as exigências dos requisitos acima, as notas têm sido dadas com excessivo rigor, tendo-se a considerar ainda que isto somente coubesse em Escolas de Belas Artes, onde os alunos são de antemão selecionados; d) tais notas virão prejudicar sensivelmente os alunos desta Escola Normal em face de um concurso para o ingresso ao magistério, levando vantagem os alunos de outras escolas onde esta matéria geralmente serve de auxílio às outras. [...] Pelo exposto a V. S. pensamos ter agido da melhor forma possível em não comparecer às aulas a contar de hoje, terça-feira, até sábado da presente semana como sinal de protesto, fazendo-lhe, entretanto, antecipadamente, ciente de que esse não comparecimento não é absoluto indício de indisciplina, mas sim, de rogo à justiça e com a qual retornaremos à Escola. (Camargo, 1934, p. 16) 
Os alunos tinham clareza de que avaliações demasiadamente rigorosas os prejudicariam em concursos públicos e pediam mudanças neste processo. Com este propósito, a greve discente era mais um instrumento de pressão para que tais mudanças fossem implantadas na Escola Normal de Piracicaba. Cabe destacar que não se faz mais declaração de greve estudantil como antigamente. Usava-se então a cordialidade e o respeito formal à hierarquia como ferramentas úteis no convencimento da autoridade competente de que as reivindicações apresentadas eram razoáveis. Neste caso, Fausto Lex mediou reunião entre os alunos e o catedrático de Desenho, quando conseguiram chegar a um acordo:

Fausto Lex: Houve uma solução plenamente satisfatória. Em entendimento que promovi entre o referido professor [de Desenho, Antonio de Pádua Dutra] e uma grande comissão de alunos, [em duas horas de conversa] ficou tudo resolvido satisfatoriamente para ambas as partes e os alunos voltaram a frequentar as aulas normalmente. Com referência ao fato de se fazer exame de desenho em caráter de "trabalho proposto", como determinou o sr. Diretor Geral [do Ensino], o professor Dutra declarou submeter-se. (Camargo, 1934, p. 11 verso)

Buscou-se, novamente, nas determinações da Diretoria Geral do Ensino a maneira de facilitar as avaliações discentes. Mesmo cedendo o catedrático de Desenho explicou à autoridade sindicante que a constante pressão estudantil na forma de greves estava conturbando continuamente o cotidiano escolar e prejudicando o aprendizado:

Antonio de Padua Dutra, catedrático de Desenho: Convém esclarecer que essa atitude dos estudantes, manifestando-se em greve, não é a primeira neste estabelecimento de ensino, pois que constantemente há greves de alunos a ponto de não poderem os demais professores dar a matéria com regularidade. (Camargo, 1934, p. 43 verso)

Em 1934 o movimento estudantil brasileiro encontrava-se em acirrada batalha pela mudança nos processos de avaliação do ensino. Como se processava a avaliação do ensino secundário e do ensino superior até este período? Até 1934, para efeito de promoção do aluno, considerava-se exclusivamente a nota obtida nos exames finais de dezembro. Qual a função das provas parciais de abril, julho e setembro? Existiam apenas para verificar se o aluno estava apto para prestar os exames finais de dezembro. Podiam prestar as provas finais em dezembro aqueles que comprovassem a frequência mínima de dois terços das aulas de cada cátedra a ser examinada e que tivessem obtido, no mínimo, a média 5,0 nos exames parciais de cada disciplina. Porém, as notas destes exames parciais não eram contabilizadas na nota dos exames de dezembro, somente esta última era levada em consideração na promoção ou não do aluno para o ano seguinte. Caso reprovado nos exames finais de dezembro os alunos poderiam fazer novamente exames em uma segunda época, na primeira quinzena de fevereiro do ano seguinte, antes do início do próximo ano letivo.

No caso específico do Estado de São Paulo havia esperanças, no movimento estudantil, de que a criação da Universidade de São Paulo no início do ano trouxesse mudanças no sistema de avaliação. No entanto, com a divulgação, em meados de 1934, dos diversos regulamentos das unidades incorporadas à USP, constatou-se que nada 
havia mudado no processo avaliativo do ensino superior. No segundo semestre de 1934 a luta do movimento estudantil concentrou-se na reivindicação da mudança da sistemática avaliativa pela adoção da promoção pelas médias. Os estudantes mobilizaram-se nacionalmente para conseguir esta mudança.

Em 26 de julho de 1934 Gustavo Capanema foi nomeado Ministro da Educação e Saúde Pública. Getúlio Vargas não desejava um confronto desgastante com o movimento estudantil. Para evitar isto Gustavo Capanema articulou para que o deputado mineiro José Monteiro Ribeiro Junqueira apresentasse o projeto estabelecendo a promoção pelas médias como mecanismo de avaliação discente no ensino secundário e no ensino superior. Este foi o primeiro projeto de iniciativa parlamentar a ser aprovado em rápida tramitação pela recente legislatura iniciada neste mesmo ano. Em dezembro, às vésperas dos exames finais e sob constantes boatos de que Getúlio Vargas sancionaria a lei da promoção pelas médias ainda em 1934, a Frente Única dos Estudantes, em São Paulo, organizou greves no ensino superior e no ensino secundário para pressionar o governo paulista a adotar a promoção pelas médias neste mesmo ano. Na Capital, os alunos da Escola Politécnica e da Faculdade de Direito, recém-incorporadas à USP, entraram em greve. Os alunos do Instituto de Educação, a anterior Escola Normal de São Paulo, entraram em greve pelos mesmos motivos. No dia 7 de dezembro seria a vez da Escola Normal de Piracicaba também entrar em greve em apoio à reivindicação da promoção pelas médias. A Gazeta de Piracicaba, de 8 de dezembro de 1934, noticiou a greve:

\begin{abstract}
Estão agitados os meios estudantis com a questão da promoção por média. Ainda ontem houve uma reunião dos alunos do Curso Fundamental da Escola Normal Oficial, no Teatro Santo Estevam, à qual compareceram cerca de 300 alunos. [...] Durante a sessão, que decorreu agitada, fizeramse ouvir os seguintes estudantes: Carlos Barbosa, João Narche [o mesmo que em julho se recusara a fazer a prova de Francês sem o uso de dicionário], Pedro Neme, Francisco Almeida Prado e Orlando Regitano. Após calorosos debates ficou resolvido que os alunos do Curso Fundamental aderiam à greve que se alastra por todo o país. [...] É o seguinte teor do telegrama transmitido ao Centro Acadêmico XI de Agosto [da Faculdade de Direito da USP, onde se organizava a Frente Única dos Estudantes]: ao Comitê Central da Greve - Cerca [de] trezentos alunos [do] Curso Fundamental [da] Escola Normal Oficial [de Piracicaba] confiantes [na] vitória aderem [à] causa [dos] estudantes brasileiros.
\end{abstract}

Na capital a greve se agravou em meados de dezembro. O jornal Correio Paulistano, de 15 de dezembro de 1934, p. 5, noticiou que na véspera os estudantes da Escola Politécnica lacraram a sala do Conselho Universitário da USP e impediram a sua reunião. O Conselho Universitário ameaçou renúncia coletiva caso não tivesse segurança para se reunir. Houve repressão policial à greve no Instituto de Educação. Segundo o Correio Paulistano, de 16 de dezembro de 1934, p. 5, "os estudantes continuam em greve. Vai por essas ruas uma confusão, um barulho enorme. Há coisas desagradáveis, como a da Escola Normal Padre Anchieta, em que a polícia paulista chegou ao cúmulo de agredir as alunas." 
Com a notícia de que Getúlio Vargas, em 18 de dezembro de 1934, sancionara sem vetos a lei de promoção pelas médias, os diversos grêmios acadêmicos paulistas convocaram assembléias visando encerrar a vitoriosa greve estudantil. No Correio Paulistano, de 19 de dezembro de 1934, p. 3, a estudante Isabel Ferrer apresentou os propósitos do movimento:

Em primeiro lugar, visa tornar a cultura efetivamente um direito de toda a população, uma conquista que tem de ser levada a todo o povo, atingindo principalmente a suas camadas pobres. Liquidar o analfabetismo. Impedir o processo de formação de falsas elites, que viriam cada vez mais restringir o círculo de pessoas com direito a estudar, que tornariam cada vez mais penosa a atmosfera de asfixia intelectual em que vive o povo brasileiro, [...] [colaborando para] a manutenção do estado de imbecilização em que à força se quer manter o povo. [...] Em segundo lugar, trata-se duma transformação completa dos métodos de ensino. Nossa legislação escolar e nossos programas de ensino parecem hoje destinados mais a frear o processo de formação das inteligências, que a fornecer-Ihes elementos para isso. Legislação medieval, pré-histórica, ignorando os mais comezinhos princípios da ciência moderna, construída de propósito para lançar anualmente, num ambiente radicalmente diverso daquele para o qual estavam preparados, fornadas inteiras de jovens que se vêem completamente desorientados e incapazes, tal a diferença entre o que aprenderam e o que vão depois viver. Finalmente, liquidar com o regime carcerário que dirige a vida de nossas escolas e introduzir um sistema de vida escolar absolutamente novo - sadio, arejado - que fará com que as casas de ensino, principalmente as secundárias, deixem de ser consideradas, pelos estudantes, como são atualmente, casas de correção, casernas militarizadas.

Nota-se aqui a sensação de plena liberdade, otimismo e de euforia democrática descrita no início deste artigo. A luta do movimento estudantil foi crucial para que Getúlio Vargas sancionasse sem vetos a lei de promoção pelas médias. Mesmo tendo sido publicada no Diário Oficial em 21 de dezembro de 1934, ela saiu com a data de 12 de dezembro de 1934. Assim, embora publicada após o período de exames finais, que ocorreram desde 15 de dezembro, sua data era anterior a tais exames. Dependeu da pressão estudantil, caso a caso, para que ela tivesse sido aplicada já para o ano letivo de 1934, que chegava ao seu fim, ou para o ano seguinte. De qualquer forma, foi uma conquista significativa da mobilização discente.

A lei n. 11 , de 12 de dezembro de 1934 , entre outros temas, estabelecia no art. $2^{\circ}, \S$ $1^{\circ}$ que "a nota de cada disciplina do curso secundário será a média ponderada de trabalhos escolares e provas parciais". De maneira inovadora trabalhos escolares puderam ser computados no processo de avaliação educacional. Os alunos secundaristas também lutaram pela abolição das provas orais, mas a sua possibilidade foi mantida nesta legislação. Em relação ao ensino superior a lei era clara e sucinta. Art. 50: "Nos cursos superiores, sem exceção, o aluno que obtiver média igual ou superior a seis, em qualquer cadeira, ficará dispensado, na referida cadeira, de exame final para promoção ao ano seguinte ou aprovação final [conclusão do curso]. $\S$ único: A nota final em cada cadeira será a média aritmética das provas parciais". 
Retornando aos acontecimentos na Escola Normal de Piracicaba, o que propuseram os professores ouvidos pela autoridade sindicante para solucionar aquela situação conflituosa? Resumidamente: reivindicaram maior participação docente na gestão escolar. Em outras palavras, propuseram a instalação da Congregação da Escola Normal de Piracicaba. A Congregação era o órgão colegiado que reuniria a direção, os catedráticos e uma pequena representação discente para tratar dos aspectos importantes da vida escolar.

Frente à autoridade sindicante, Antonio de Padua Dutra, catedrático de Desenho, foi propositalmente irônico ou cometeu involuntariamente um ato falho quando tocou neste assunto. Ele chamou o diretor de Falso Lex, ou seja, falsa lei:

Antonio de Padua Dutra: Embora tenha sido desejo de todos os professores a instalação e reunião da Congregação, instituída pelo Código de Educação, o professor Falso Lex, digo, Fausto Lex, alegando não ser possível essa providência, por não estar ainda a escola sob fiscalização federal, bem como devido à divergência do corpo docente, não instalou nem reuniu esse instituto. (Camargo, 1934, p. 44)

Vários outros professores sugeriram à autoridade sindicante a instalação da Congregação da Escola Normal de Piracicaba como solução para os impasses existentes:

Manoel Dias de Almeida, catedrático da Escola Normal: Apesar de instituída pelo Código de Educação, [...] a Congregação, que deve existir nos cursos fundamentais das Escolas Normais, não foi instalada nesta escola. (Camargo, 1934, p. 49)

Fausto Lex alegava que reunia, quando necessário, o corpo docente para comunicar assuntos referentes ao ensino, mas ainda não instalara a congregação por uma questão de respeito à hierarquia funcional do serviço público federal:

Fausto Lex: Tenho reunido os professores sempre que há necessidade de tomar conhecimento de assuntos referentes ao ensino, sem, entretanto, dar o caráter de Congregação, por não ter sido nomeado e empossado o inspetor federal, isso com o conhecimento da Chefia do Serviço do Ensino Secundário e Normal [em São Paulo], que não desaprovou [meu procedimento]. (Camargo, 1934, p. 135 verso)

Alguns professores não exigiam que se chamasse de congregação, mas que o diretor se reunisse com o corpo docente para resolver coletivamente o mal-estar existente na escola:

Carlos Martins Sodero, catedrático da Escola Normal: Há na escola uma atmosfera de intranquilidade desagradável, criada pela administração do professor Fausto Lex; as classes são tristes e o professorado queixoso; esta situação reflete-se sobre a finalidade da escola, pela falta de estímulo que acarreta; é possível sanar-se esta situação mediante um novo rumo que adote o diretor Fausto Lex, procurando ouvir os professores em reuniões, adotando atitudes e processos diversos dos que põe em prática [atualmente]. (Camargo, 1934, p. 110 verso) 
Dario Brasil, catedrático de Latim: O estado de coisas anormal que se nota nesta escola é devido às exigências descabidas do diretor e à diversidade de interpretação dada às leis por professores e diretor; esta disparidade de hermenêutica não haveria se houvesse sido instalada no estabelecimento a Congregação criada pelo Código de Educação; a instalação da Congregação nesta Escola Normal será o meio de se remediar os males existentes, com a transigência da parte do diretor e da [parte] dos professores. (Camargo, 1934, p. 117)

A solução apontada consensualmente pelos professores inquiridos pela sindicância era a instalação da Congregação da Escola Normal de Piracicaba. Neste órgão colegiado os conflitos e divergências poderiam ser sanados e a normalidade institucional seria restabelecida nesta importante instituição de ensino.

Quais os resultados da sindicância sobre os conflitos na Escola Normal de Piracicaba? Em seu relatório José de Campos Camargo, a autoridade sindicante, indicou ao diretor geral do ensino que Manassés Ephraim Pereira incorrera efetivamente em desobediência e desacato à autoridade competente. Este professor foi punido com a pena de censura escrita, aplicada pelo diretor geral do ensino. (Camargo, 1934, p. 155) Foi recomendado o afastamento definitivo do professor interino de Português, Silvio de Aguiar Souza. Isto não ocorreu. Posteriormente, Silvio de Aguiar Souza tornou-se catedrático na Escola Normal de Piracicaba. Fausto Lex continuou, por algum tempo, como diretor da escola. Participou, em dezembro, das cerimônias de formatura dos graduandos de 1934, sendo homenageado nesta ocasião. Porém, sua sorte estava selada. A estratégia para sua saída não traumática da direção da Escola Normal foi sugerida pela autoridade sindicante:

José de Campos Camargo: Durante o longo mês de sindicância, tive oportunidade de observar de perto o professor Fausto Lex. É um homem de aparência robusta, mas de saúde combalida. Não atinge uma só vez o topo da escada sem sentir-se afrontado; qualquer emoção o deixa com dispnéia e transfigurado. Sua voz toma, então, um timbre e um diapasão nervoso e é interrompida frequentemente pela tosse característica das afecções cardíacas, especialmente das insuficiências mitrais. Sua vida dentro da Escola Normal de Piracicaba é um sofrimento contínuo e uma agravação permanente do seu estado de saúde, devido à situação anormal em que se acha em relação ao corpo docente do estabelecimento, o que faz com que esteja sempre em expectativa de emoções e contrariedades. (Camargo, 1934, p. 153)

Para não desautorizar Fausto Lex, o diretor geral do ensino adiou a substituição do diretor da Escola Normal. Deixou terminar o ano letivo antes de agir. Em 30 de janeiro de 1935 Fausto Lex foi convocado para exame médico na capital. É provável que com esta convocação a São Paulo, o diretor tenha aproveitado para conversar pessoalmente com Fausto Lex e tenha explicado sua posição insustentável como diretor da Escola Normal de Piracicaba. No início de 1935 Fausto Lex pediu aposentadoria. Em 30 de abril de 1935 Fausto Lex foi aposentado por problemas de saúde. O Jornal de Piracicaba, de 4 a 7 de maio de 1935, descreveu detalhadamente as homenagens recebidas e a cerimônia de despedida de Fausto Lex. 
Manassés Ephraim Pereira lecionou na Escola Normal de Piracicaba até a segunda metade da década de 1950, quando se aposentou após meio século em exercício no magistério.

O diretor que sucedeu Fausto Lex na Escola Normal foi nomeado pelo governador em 25 de junho de 1935. Tomou posse na Escola Normal de Piracicaba em 4 de julho de 1935, um ano depois dos conflitos que determinaram a saída de Fausto Lex. O novo diretor era Thales Castanho de Andrade. Este professor, embora tenha sido acusado de conivência com as fraudes nos exames escolares, tinha ótimo relacionamento com a elite intelectual paulista do período.

Quanto ao projeto de criação da nova Escola Normal Rural em Piracicaba, se parte da elite intelectual paulista mal conseguia conviver pacificamente na escola normal existente, o que ocorreria com a implantação de uma segunda escola normal na cidade? Este projeto foi abortado e seu decreto de criação tornou-se letra morta.

Enfim, com os acontecimentos aqui narrados constatou-se como numa tradicional instituição de ensino, mesmo que bem intencionada, a direção perdeu o rumo. A nau da Escola Normal de Piracicaba espatifou-se contra os arrecifes do novo Código de Educação. Recuperar seus destroços nos ajuda a entender as tempestades sociais da tumultuada década de 1930.

\section{Referências}

CAMARGO, José de Campos. Sindicância procedida na Escola Normal Oficial de Piracicaba por determinação do diretor geral do ensino. São Paulo: Diretoria Geral do Ensino, 1934. Documento preservado no Arquivo Público do Estado de São Paulo sob a indexação E 07028.

HILSDORF, Maria Lúcia Spedo. Lourenço Filho em Piracicaba. In: SOUZA, Cynthia Pereira de (org.). História da educação: processos, práticas e saberes. São Paulo: Escrituras, 1998, p. 95-112.

MACIONIRO CELESTE FILHO é professor na Universidade Estadual Paulista campus de Bauru. Doutor em Educação pela Pontifícia Universidade Católica de São Paulo.

Endereço: Av. Paes de Barros, 1252/22 - 03114-000 - São Paulo - SP - Brasil.

E-mail: marcio.celeste@fc.unesp.br.

Recebido em 12 de janeiro de 2015.

Aceito em 4 de outubro de 2015. 